\title{
THE BENEFICIAL EFFECT OF CHLOROMYCETIN IN BRUCELLOSIS ${ }^{1,2}$
}

\author{
By THEODORE E. WOODWARD, 3 JOSEPH E. SMADEL, WILLIAM A. \\ HOLBROOK, ${ }^{5}$ AND WILLIAM T. RABY ${ }^{\circ}$ \\ (From the Department of Medicine, University of Maryland School of Medicine, and the \\ Department of Virus and Rickettsial Diseases, Army Medical Depart- \\ ment Research and Graduate School)
}

Newer antibiotic agents have greatly extended the range of specific therapy in the group of infectious diseases with increasing rapidity. Much of this effort is directed against gram-negative bacilli in which group the Brucellae command a prominent position. Up to the present time the use of therapeutic agents in brucellosis has resulted in a certain measure of success, but with limitations, particularly from the point of view of failure to prevent recurrences.

One of these new antibiotics is chloramphenicol (Chloromycetin) a streptomyces, first isolated by Burkholder," crystallized by Ehrlich and his associates (1) and demonstrated to possess potent antimicrobial effect against many gram-negative organisms including all members of the Brucella group (2). The pharmacological and toxicological characteristics of this new agent are now a matter of record (2) and the chemical structure of the antibiotic agent is known. (3). In experimental and clinical infections the synthetic form of Chloromycetin has been found comparable to the naturally produced product in degree of effectiveness (4).

Chloromycetin is well absorbed from the gastrointestinal tract. Serum levels of the drug after oral administration have been found comparable to those obtained by parenteral administration.

\footnotetext{
1 Presented at the Second National Symposium on Recent Advances in Antibiotics Research held in Washington, D. C., April 11-12, 1949, under the auspices of the Antibiotics Study Section, National Institutes of Health, Public Health Service, Federal Security Agency.

2 This study was supported by a grant from the Clinical Division, Parke, Davis and Company.

8 Associate Professor of Medicine.

4 Director of the Department of Virus and Rickettsial Diseases, Army Medical Department Research and Graduate School.

- Assistant in Medicine.

- Resident in Medicine.

7 Dr. Paul R. Burkholder, Osborn Botanical Laboratory, Yale University.
}

There are no reports up to the present time of toxic manifestations resulting from the oral administration of Chloromycetin. The prolonged intramuscular administration in dogs resulted in a moderately severe anemia without significant changes in the white blood cells and without disturbance in hepatic or renal functions (2).

The initial studies of the antibiotic spectrum of Chloromycetin in vitro and in vivo in animals indicates a wide range of usefulness, particularly in rickettsial and gram-negative infections $(2,5)$. Among the gram-negative organisms showing a considerable degree of sensitivity to this antibiotic are Brucella abortus, Brucella melitensis and Brucella suis. It is interesting to point out that up to the present time Chloromycetin has not failed to exert great beneficial effect in those clinical diseases whose organism has been found sensitive to the agent when tested in the laboratory.

In Maryland the opportunity to treat brucellosis afforded itself because of a rather prevalent incidence of the $B$. abortus and $B$. suis types of infection. We have observed nine patients with active infection during the period from July, 1948, to February, 1949. Six of these patients were experiencing an initial attack, whereas three patients showed a relapse of fever two, three and five months after the primary illness treated with a combined course of streptomycin and sulfadiazine. The present study deals with the results obtained following Chloromycetin administration in these nine patients. Observations on non-treated cases (controls) were not made because of the insufficient number of available patients.

\section{METHODS AND PROCEDURE}

Chloromycetin was administered orally, the antibiotic having been furnished by Parke, Davis and Company in the form of $0.25 \mathrm{gm}$. tablets and capsules. The tablets were swallowed whole and in spite of the bitter taste no difficulty was experienced with oral administration. Chlo- 
romycetin now supplied in gelatin capsules is taken orally without unpleasantness.

The dosage regimen adopted for this study was empirical and based, in general, on prior experience in scrub typhus and typhoid fever $(6,7)$. The large initial dose in each instance was approximately $50 \mathrm{mg}$. per kilo. After the initial dose, Chloromycetin was given at three hour intervals in $0.25 \mathrm{gm}$. amounts until the temperature was normal and for a minimum of five days thereafter.

Blood levels for Chloromycetin were determined throughout the period of treatment. A modification of the method of Joslyn and Galbraith (8) which employs inhibition of growth of Shigella sonnei was used for these micro-biological assays. The sensitivity of the brucella was determined by inoculating a standard quantity of the bacterial suspension into serial dilutions of Chloromycetin in tryptocase broth. After approximately three days' incubation, the sensitivity was determined turbidimetrically by the $\mathbf{5 0}$ per cent end-point technique as applied to fluid culture.

Confirmation of the clinical diagnosis of brucellosis was sought in each instance through the following procedures: (1) Blood was taken from the patient for culture before instituting treatment. Venous blood was inoculated directly into tryptocase broth which was then incubated at a temperature of $37^{\circ} \mathrm{C}$. in an atmosphere of 10 per cent carbon dioxide. Subcultures were made on tryptocase agar utilizing the same conditions. Blood cultures were repeated on each patient at least three times during the period of hospitalization and one month following discharge from the hospital when the first followup studies were performed. (2) Agglutination tests, utilizing $B$. abortus as antigen, were performed by the usual clinical laboratory techniques.

Hemoglobin levels, red and white blood cell counts and differential leukocyte counts were performed in the usual manner.

\section{RESULTS}

a. Confirmation of diagnosis: In seven of the nine patients constituting this series of treated pa- tients, four showed a positive blood culture for $B$. abortus, two for $B$. suis and one for $B$. melitensis prior to the administration of Chloromycetin. All of the post-treatment blood cultures remained sterile. In all nine patients a significantly high rising titer for brucella agglutinins was demonstrated (Table I).

b. Blood levels of Chloromycetin and sensitivity tests: The levels of Chloromycetin in the blood were found to be comparable to those obtained and reported elsewhere (9). For 24 hours following the initial dose of the antibiotic, the level ranged in seven patients tested from 10 to 50 gamma per cc. During the ensuing therapeutic days when the patients were on a comparable dose of $.25 \mathrm{gm}$. every three hours the average level was 15 gamma per cc. up to the time of cessation of therapy. The sensitivity of the infecting organisms tested on four patients ranged from .78 to 2.4 gamma per cc. (Table I). These concentrations compare favorably with the figures reported by Smith et al. (2) who had previously demonstrated inhibition of Brucellae to Chloromycetin in the following concentrations: $B$. abortus, 2.0 gamma per cc.; $B$. suis and $B$. melitensis, 0.5 gamma per cc.

\section{The course of undulant fever in patients treated with Chloromycetin}

The mean duration of fever prior to treatment in the nine treated patients was 30 days. Two of these patients were more seriously ill than the others. Within 36 hours after the start of specific treatment they were resting more comfortably, spent a more restful night for the first time since

TABLE I

Tabulation of results on the use of Chloromycetin in brucellosis

\begin{tabular}{|c|c|c|c|c|c|c|c|c|c|c|c|c|c|}
\hline \multirow[t]{2}{*}{ Case } & \multirow{2}{*}{ Age } & \multirow{2}{*}{ Sex } & \multirow{2}{*}{$\begin{array}{l}\text { Day of } \\
\text { illness } \\
\text { therapy } \\
\text { beg. }\end{array}$} & \multirow{2}{*}{$\begin{array}{c}\text { Duration } \\
\text { fever } \\
\text { aft. } \\
\text { therapy }\end{array}$} & \multirow{2}{*}{$\begin{array}{c}\text { Last } \\
\text { febrile } \\
\text { day of } \\
\text { illness }\end{array}$} & \multirow{2}{*}{$\begin{array}{l}\text { Size of } \\
\text { spleen }\end{array}$} & \multicolumn{2}{|c|}{ Chloromycetin } & \multicolumn{2}{|c|}{ Agglutination } & \multirow{2}{*}{$\begin{array}{c}\text { Blood } \\
\text { culture }\end{array}$} & \multirow{2}{*}{$\begin{array}{l}\text { Sensi- } \\
\text { tivity }\end{array}$} & \multirow{2}{*}{$\begin{array}{l}\text { Maximum } \\
\text { blood level }\end{array}$} \\
\hline & & & & & & & & & Acute & Conv. & & & \\
\hline $\begin{array}{l}1 \\
2 \\
3 \\
4 \\
5 \\
6 \\
7 \\
8 \\
9\end{array}$ & $\begin{array}{l}27 \\
31 \\
32 \\
28 \\
29 \\
38 \\
24 \\
31 \\
26\end{array}$ & $\begin{array}{l}\mathbf{M} \\
\mathbf{F} \\
\mathbf{M} \\
\mathbf{M} \\
\mathbf{M} \\
\mathbf{M} \\
\mathbf{M} \\
\mathbf{M} \\
\mathbf{M}\end{array}$ & $\begin{array}{l}53 \text { rd } \\
12 \text { th } \\
25 \text { th } \\
19 \text { th } \\
23 \text { rd } \\
57 \text { th } \\
32 \text { nd } \\
25 \text { th } \\
28 \text { th }\end{array}$ & $\begin{array}{l}2.0 \\
2.0 \\
2.5 \\
2.0 \\
3.0 \\
4.5 \\
2.0 \\
2.0 \\
5.5\end{array}$ & $\begin{array}{l}55 \\
14 \\
27 \\
21 \\
26 \\
61 \\
34 \\
27 \\
33\end{array}$ & $\begin{array}{c}++ \\
+ \\
+++ \\
++ \\
0 \\
+ \\
+ \\
0 \\
++\end{array}$ & $\begin{array}{c}\text { total } \\
\text { days } \\
6 \\
6 \\
9 \\
6 \\
8 \\
12 \\
10 \\
8.0 \\
10\end{array}$ & 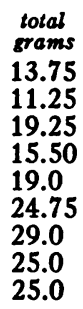 & $\begin{array}{r}1280 \\
80 \\
640 \\
320 \\
640 \\
1280 \\
1280 \\
640 \\
640\end{array}$ & $\begin{array}{r}2560 \\
1280 \\
640 \\
1280 \\
640 \\
1280 \\
1280 \\
640 \\
10,000\end{array}$ & $\begin{array}{l}\text { Abortus } \\
\text { Suis } \\
\text { Suis } \\
\text { Abortus } \\
\text { Abortus } \\
\text { Abortus } \\
\text { Melitensis }\end{array}$ & $\begin{array}{l}r / c c . \\
2.4 \\
- \\
\overline{1.2} \\
.78 \\
1.2 \\
- \\
-\end{array}$ & $\begin{array}{l}\gamma / c c . \\
50 \\
18 \\
12 \\
10 \\
33.5 \\
24.9 \\
16.0 \\
- \\
-\end{array}$ \\
\hline \multicolumn{3}{|c|}{ Mean } & 30.3 & 2.7 & 33.0 & & 8.3 & 20.28 & & & & & \\
\hline
\end{tabular}


the onset of illness and diaphoresis was greatly reduced. In the seven other patients there seemed to be immediate improvement of the body and joint pain and there was decidedly improved taste for food.

The mean in the nine patients for duration of fever after beginning Chloromycetin treatment was 2.7 days. The temperature in all remained normal thereafter. Seven of the nine patients had enlarged spleens felt from one to three fingers below the costal margin. In five patients the spleen was observed to become non-palpable during the course of antibiotic treatment and in the remaining two the spleen disappeared to palpation several days after stopping the drug. The response to treatment in six patients is best demonstrated in figures 1-6 which are accompanied by brief clinical records.

\section{Occurrence of complications}

a. Relapses: There was one relapse, the recurrence beginning 31 days following discontinuance of Chloromycetin. Although we were unsuccessful in re-isolating the $B$. abortus from the blood, it is of considerable importance that the re- administration of Chloromycetin resulted in a prompt clinical response.

b. Complications: In the group constituting this series of nine treated patients there were no complications attributed to brucellosis observed after Chloromycetin treatment. The patient with the melitensis type infection developed an orchitis three months following sulfadiazine and streptomycin treatment. Two days after receiving Chloromycetin the patient noted a definite improvement not only in reduction in size of the testicle but a marked reduction in tenderness.

\section{Illustrative Case Reports}

Case No. 1. (Figure 1.) The patient was a 27-yearold Negro who contracted illness from drinking raw milk. He was hospitalized at Fort Meade on the 29th day of disease. His early complaints were primarily those of fever, profuse sweating, headache, anorexia, general weakness, and malaise. After admission the evening temperature reached $105^{\circ} \mathrm{F}$. and ranged from 102 to $105^{\circ}$ prior to the administration of specific therapy. His nights were restless because of the pyrexia, sweating and general aching. There were no signs of a localized infection. On the 32nd day of illness culture of the blood was positive for $B$. abortus. The organism isolated was sensi-

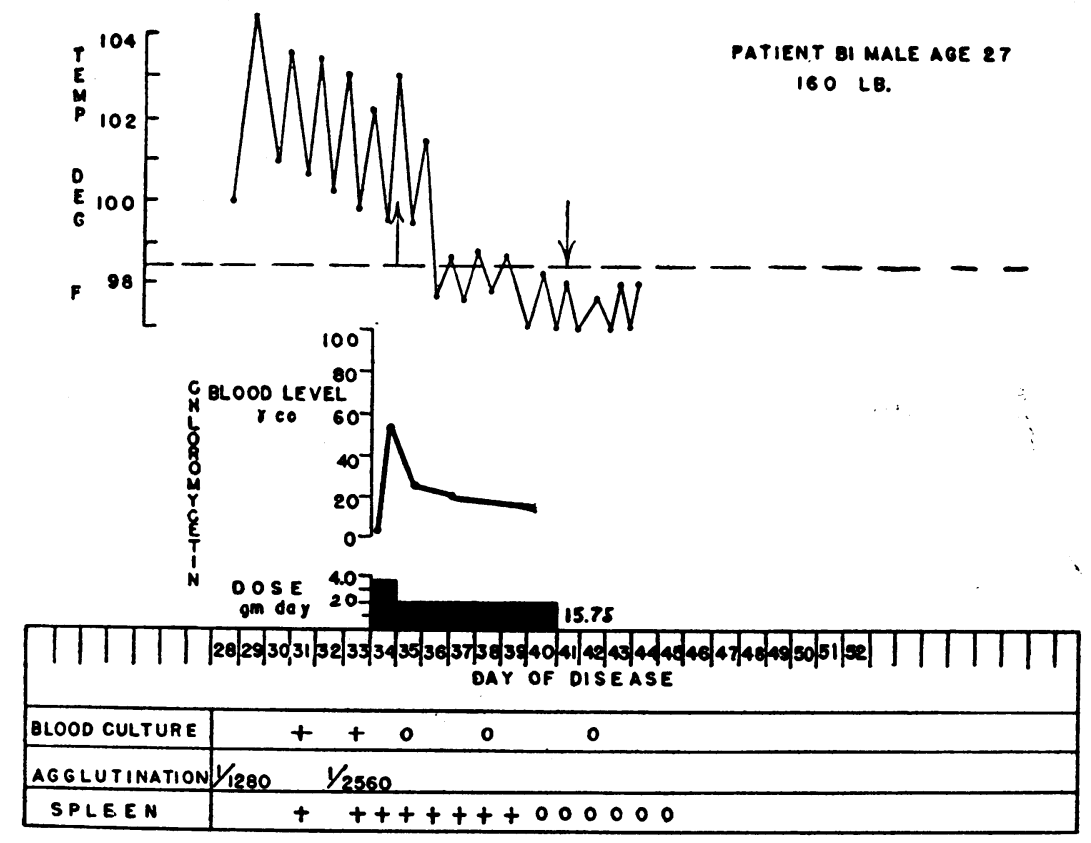

Fig. 1. (Case No. 1.) Chart of Regults in a Patient (Male, Age 27, 160 Lbs.) with Brucellosis of Abortus Type-Treatment with ChloroMYCETIN 


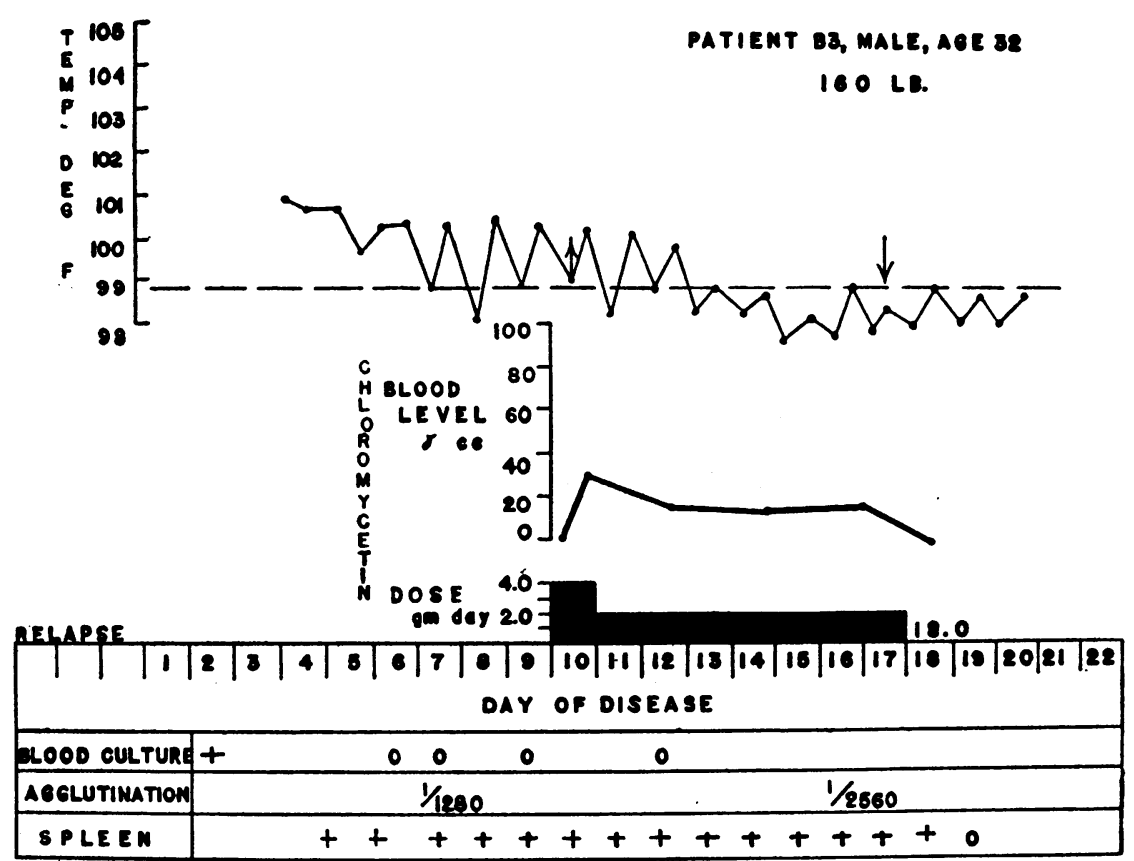

Fig. 2. (Case No. 3.) The Course of Illness in a Patient (Male, Age 32, 160 Lbs.) with Brucellosis of Suis Type-Treatment with ChloroMYCETIN

tive to Chloromycetin in the concentration of 2.4 gamma per cc. At this time the serum agglutination for $B$. abortus was $1 / 2560$. The spleen was readily palpable and there were scattered rales throughout both lungs. Chloromycetin was given orally with an initial dose of $3.0 \mathrm{gms}$. and a subsequent dosage of $.25 \mathrm{gm}$. every three hours. The drug was well tolerated. On the first night of drug treatment the patient was more comfortable and diaphoresis was greatly reduced. On the following day the appetite was decidedly improved and the bedside appearance was brighter. The evening temperature reached normal 48 hours after institution of treatment and remained normal thereafter. The spleen could not be felt after five days of therapy. A total of $15.75 \mathrm{gms}$. of Chloromycetin was administered, the course extending until five days of normal temperature. Three blood cultures taken during the convalescent period were sterile. The patient was discharged 25 days after the institution of Chloromycetin and now remains free of symptoms.

Case No. 3. (Figure 2.) A 32-year-old white man first became ill in June, 1948, with evening fever, anorexia, general malaise, weakness and chilly sensations. For one year the patient had been employed in a slaughter house participating in the slaughtering of cattle, hogs and in the packing of meat. For the initial attack he received combined streptomycin and sulfadiazine. At this time the spleen was enlarged, firm and smooth to palpation and descended two finger breadths below the costal margin. The agglutinins for $B$. abortus rose from $1 / 1280$ to $1 / 10,240$. The temperature became normal after seven days of this combined treatment but the spleen did not appreciably change in size. Two months later the patient noticed a recurrence of symptoms, the evening temperature reached $104^{\circ} \mathrm{F}$. and the spleen was readily palpable. The serum agglutination titer was $1 / 1280$ and the blood culture was positive for $B$. suis. Chloromycetin was administered with an initial dose of $50 \mathrm{mg}$. per kilo. beginning on the 10th day of relapse. The drug was then administered orally in $.25 \mathrm{gm}$. amounts every three hours until five days of normal temperature. The evening temperature reached normal 2.5 days following the institution of treatment, at which time the patient was asymptomatic. In six weeks the patient had no complaints, the blood cultures were sterile and the spleen was not palpable. The patient is now eight months convalescent and apparently well.

Case No. 4. (Figure 3.) A 28-year-old male contracted $B$. suis infection from handling meat in a city packing establishment. The primary attack began in June, 1948, at which time the blood culture revealed $B$. suis. The spleen was palpable on this admission. The evening temperature averaged $101^{\circ}$, and the patient complained primarily of general muscular aching along with sweating and anorexia. After three weeks of temperature a combined course of streptomycin and sulfadiazine was administered. The temperature reached normal in seven days, and the patient was generally improved. Brucellin was employed during the convalescent period which was accompanied by body pain and fever soon after administration. A persistent daily fever reappeared less than two months after the first therapeutic course. The blood revealed $B$. suis and the serum agglutinating titer 
T. E. WOODWARD, J. E. SMADEL, WILLIAM A. HOLBROOK, AND W. T. RABY
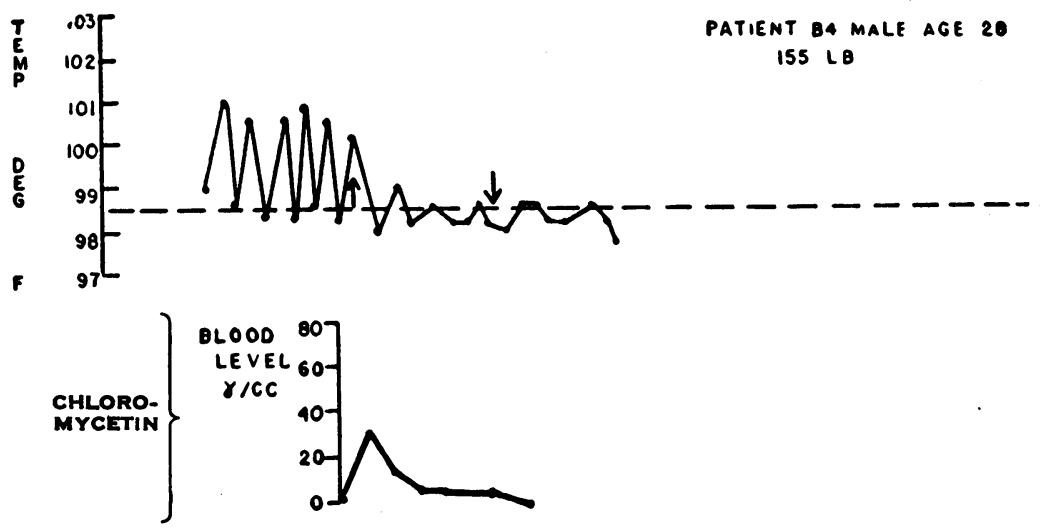

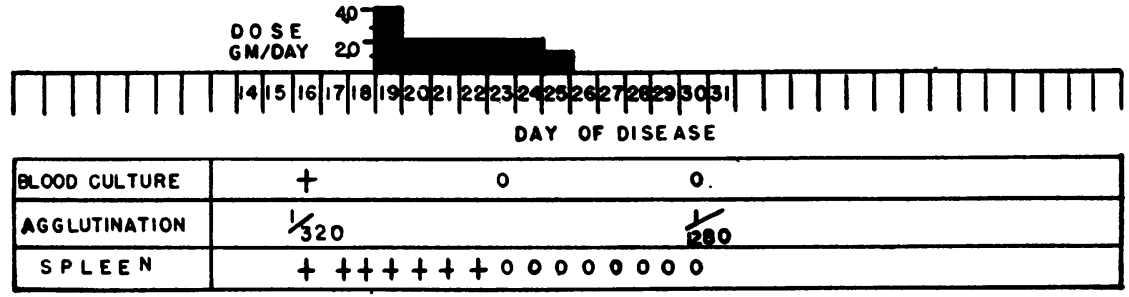

Fig. 3. (Case No. 4.) Chart of Results in a Patient (Male, Age 28, 155 Lbs.) with Brucellosis, Suis Type-Treatment with Chloromycetin No recurrence after eight months.

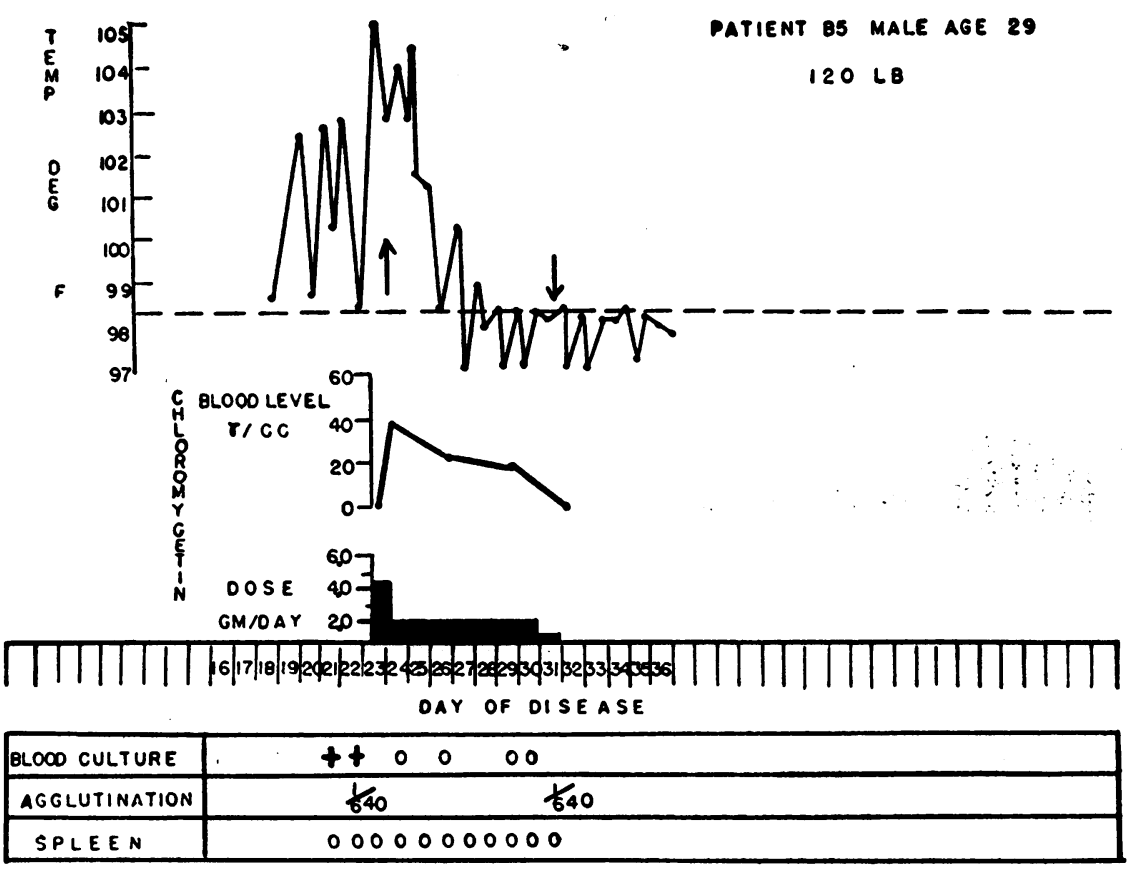

Fig. 4. (Case No. 5.) The Response to Chloromycetin in a Patient (Male, Age 29, 120 Lbs.) Severely Ill with Brucellosis (Abortus Type) No recurrence after six months. 
for $B$. abortus was $1 / 320$. The afternoon temperature reached $101^{\circ}$ and the spleen was palpable two fingers below the costal margin. A sensitivity test for the infecting organism revealed inhibition to Chloromycetin at 1.2 gamma per cc. Chloromycetin was given with an initial dose of $3 \mathrm{gms}$. and thence $.25 \mathrm{gm}$. every three hours throughout five days of normal temperature. The total amount of drug used was $15.5 \mathrm{gms}$. The temperature reached normal 48 hours after beginning of treatment. Even before the fall of temperature the patient stated that he felt better. The spleen could not be palpated on the fourth day of normal temperature. Three blood cultures taken on the fourth, 12th and 35th afebrile days were sterile. The follow-up examination four weeks following discharge revealed an asymptomatic patient whose spleen was not palpable. Eight months have now elapsed without recurrence of symptoms.

Case No. 5. (Figure 4.) A 29-year-old white man contracted undulant fever from drinking raw milk. The acute illness was characterized by upper abdominal pain, nocturnal fever, anorexia and general malaise. Blood taken on the 22 nd and 23 rd days of illness revealed $B$. abortus found sensitive to Chloromycetin in the dilution of .78 gamma per cc. The serum agglutinating titer was $1 / 640$. Before institution of treatment the evening temperature ranged from 102 to $104.5^{\circ} \mathrm{F}$., the patient appeared quite toxic and had little inclination to eat. Sweating was moderately severe. Three gms. of Chloromycetin were given orally on the 23 rd febrile day. The subsequent oral dose was $.25 \mathrm{gm}$. every three hours. The temperature reached normal after three days of anti- biotic treatment, and the general appearance was improved in half this time. The appetite rapidly returned and diaphoresis was lessened. On the fifth afebrile day the serum agglutinating titer for $B$. abortus was $1 / 640$. Blood cultures taken on the second, third, seventh, eighth and 40th post-treatment days were sterile. Six weeks after discharge from the hospital examination revealed a healthful patient who had no complaints. At this time the spleen was not palpable and the blood was sterile. Of added interest a brucellergin skin test performed during the afebrile period was negative. The patient is healthy and well seven months after his course of therapy.

Case No. 6. (Figure 5.) A 38-year-old white man acquired $B$. abortus infection from drinking unpasteurized milk in a rural area. The early illness was characterized by evening temperature, chilly sensations and severe sweating. There was upper abdominal pain with general malaise and bothersome joint pains. Anorexia was marked. On admission to the hospital on about the 50th day of illness a rather toxic individual was observed. The temperature reached $104^{\circ} \mathrm{F}$. Examination revealed a few scattered rales in the lungs and an easily palpable spleen. The agglutination for $B$. abortus was $1 / 1280$. Two blood cultures taken during his pretreatment study period were positive for $B$. abortus which was found sensitive to Chloromycetin in the dilution of 1.2 gamma per cc. Three gms. of Chloromycetin were administered on the 57 th day of illness with subsequent doses of .25 gm. every three hours until five days of normal temperature. There was no fever after 4.5 days of treatment.

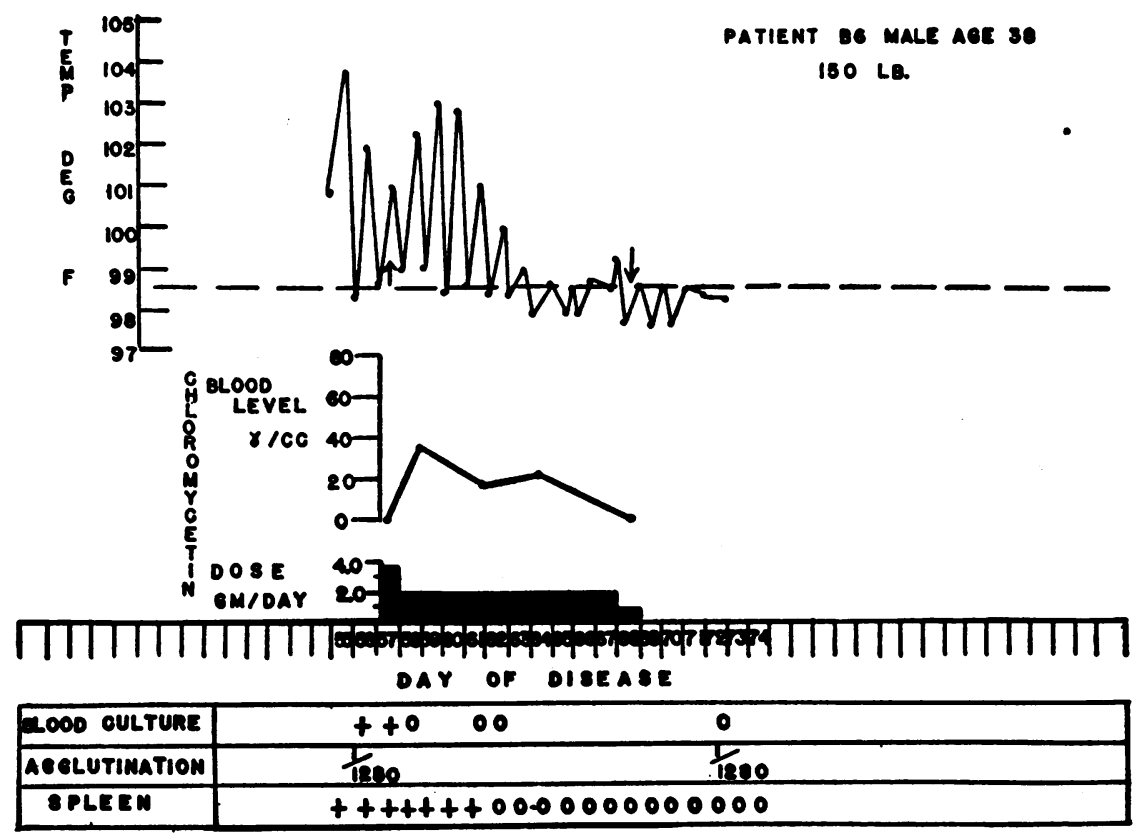

Fig. 5. (Case No. 6.) Course of Illness in a Patient (Male, Age 38, 150 Lbs.) With Abortus Type of Brucellosis-Treatment with ChloroMYCETIN

No recurrence after seven months. 
The appetite improved and sweating was lessened after two days of therapy. The spleen was not palpable on the sixth post-treatment day. The total amount of Chloromycetin used was $24.75 \mathrm{gms}$. Blood taken for culture on the second, fifth, sixth and 16th post-treatment days was sterile. The highest agglutinating titer for $B$. abortus was $1 / 1280$. Follow-up examination six weeks after discharge from the hospital revealed an afebrile patient without complaints. At the time of this examination the spleen was not palpable and the blood culture was sterile.

Case No. 7. (Figure 6.) The patient, a 24-year-old white man, acquired an abortus type of brucellosis from the butchering and sampling of meat. A prodromal period of several weeks was characterized by a profound lethargy and aching of the head and back. Fever was first observed several weeks later on about January 1, 1949 , with the evening temperature reaching $101^{\circ} \mathrm{F}$. Several days prior to hospitalization diaphoresis was pronounced and the temperature reached $104^{\circ} \mathrm{F}$. All symptoms were then accentuated, and nausea with vomiting occurred. Blood taken prior to the institution of specific treatment revealed a gram-negative organism identified as $B$. abortus. The agglutinating titer at this time was $1 / 1280$. On the 32nd day of fever Chloromycetin was administered with an initial dose of 3.0 gms., and subsequent doses of $1.0 \mathrm{gm}$. every eight hours continued in this manner until six full days of normal temperature ensued. The febrile response to therapy is represented in Figure 6. For 24 hours after starting
Chloromycetin all symptoms were greatly magnified and the patient felt worse. Decided clinical improvement marked by reduction of muscle aches and increase in strength and vigor was apparent on the second treatment day. The temperature was normal after two full days of treatment. Convalescence thereafter was rapid. A total of $29.0 \mathrm{gms}$. of Chloromycetin was administered over a period of 10 days. The highest titer attained for $B$. abortus was $1 / 1280$. Exactly 30 days after discharge from the hospital or 31 days after the last dose of antibiotic a low grade evening fever of about $99.4^{\circ} \mathrm{F}$. was noted. These rises in temperature gradually increased to $104^{\circ} \mathrm{F}$. when diaphoresis, muscle pains and gastrointestinal disturbances were experienced. Chloromycetin treatment, utilizing the prior schedule, was reinstituted, and the temperature returned to normal two days later. Blood taken during this febrile relapse did not reveal Brucellae. Judging from the rapid response after treatment with Chloromycetin, the causative organism had not gained resistance to the antibiotic.

\section{DISCUSSION}

In employing the chorioallantoic membrane of the chick, Goodpasture (10) demonstrated that Brucellae, similar to the rickettsiae, are obligate intercellular parasites which multiply within the cytoplasm of ectodermal cells. The highly specific effect demonstrated by Chloromycetin in rickett-

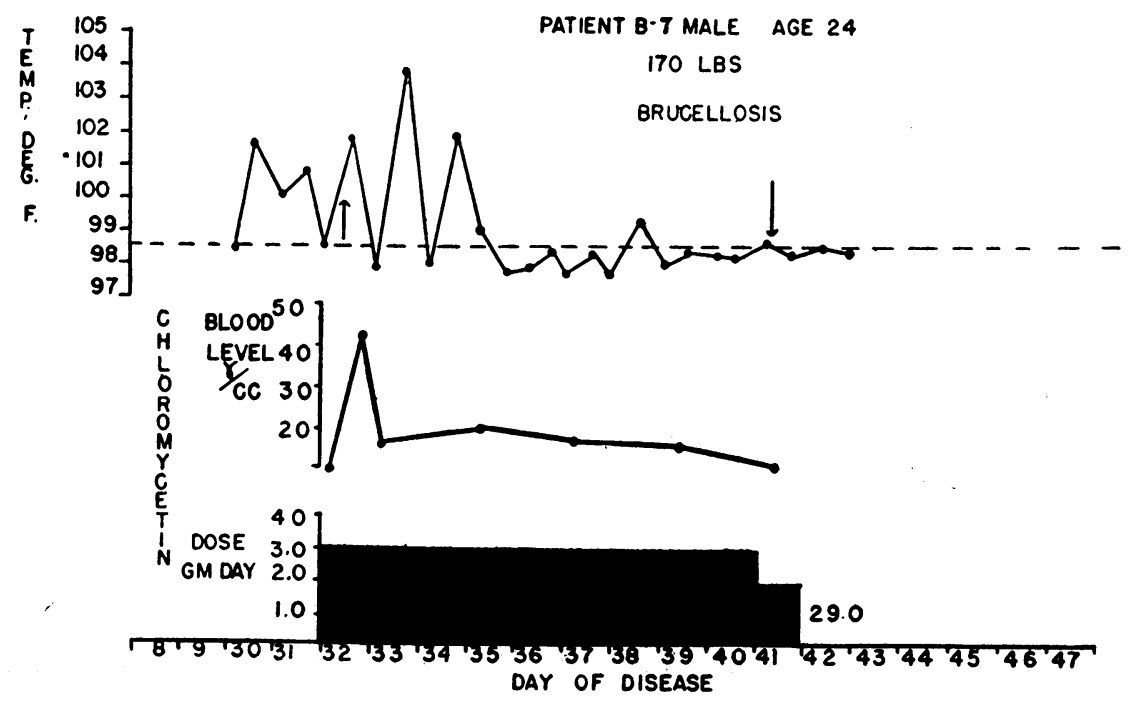

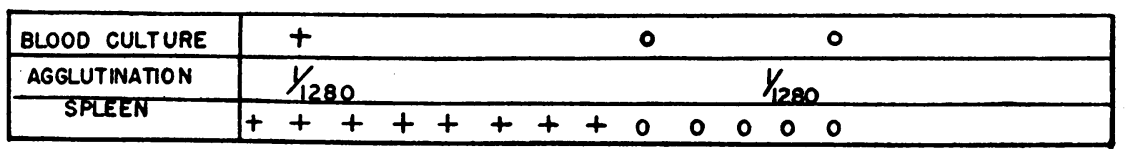

Fig. 6. (Case No. 7.) Course of Illness in a Patient (Male, Agr 24, 170 Lbs.) with Brucrllosis of AbORTUS TyPE

Patient had a relapse 30 days after discontinuing Chloromycetin. Febrile response to retreatment immediate. 
sial diseases $(6,11-13)$ is further evidence to suggest that this antibiotic might be expected to exert beneficial effect in brucellosis.

Spink and his collaborators (14) utilized the fertilized egg to demonstrate that a combination of streptomycin and sulfadiazine was sufficient to eradicate Brucellae from the tissues of infected embryos whereas they found that either drug used alone was incapable of achieving this effect. The clinical use of these combined agents in patients with brucellosis yielded more satisfactory results than had any prior treatment. In a series of treated cases these investigators (15) state that in the febrile patient normal temperatures were not sustained until the seventh to 10th days of treatment. Relapses with this form of treatment have been observed by others, and in our series of nine patients three had received treatment at an earlier date with the streptomycin and sulfadiazine regime, and were in active relapse with positive blood cultures when placed under therapy with the new antibiotic.

Detailed accounts of the successful treatment of brucellosis with aureomycin have been reported (16-18). In 24 patients with the more severe $B$. melitensis infection, Spink and his associates observed prompt reduction in toxemia and return of temperature to normal in 72 hours. Three relapses were encountered in this series up to the time of writing. In five patients with brucellosis, two proven to be abortus in type by blood cultures, we observed similar clinical improvement after aureomycin treatment (19). The temperature returned to normal in three days.

With Chloromycetin treatment in nine cases of active brucellosis we have observed abatement of symptoms within a short period and return of temperature to normal in three days after instituting treatment (Table I). One relapse occurred 30 days after discontinuing Chloromycetin. The response to retreatment was prompt. Only one patient with the more virulent melitensis type of brucellosis has been treated with this antibiotic. This patient responded favorably with return of temperature to normal in five days. It thus appears that both Chloromycetin and aureomycin exert similar favorable effect in amelioration of the symptoms of this disease, and it is not possible to affirm from the still limited accumulated evidence which antibiotic is more effective. Long term observation of a large series of patients, varied treatment schedules and observations for possible toxic effects will need study before proper evaluation of these agents can be determined in a disease so variable in its clinical manifestations. Undoubtedly, until the optimum course of treatment is determined, additional relapses will occur at which time it will be highly instructive to observe the clinical effects after reinstituting Chloromycetin and to compare the drug sensitivity of the organism causing the relapse with the one isolated during the initial attack. It is probable that longer courses of antibiotic treatment may be necessary or perhaps periodic courses of antibiotic until a sufficient degree of immunity has developed.

\section{CONCLUSIONS}

Chloromycetin has been found to exert specific beneficial effect in nine patients with active brucella infection.

Further clinical testing will be necessary to determine the optimum therapeutic regimen.

\section{ACKNOWLEDGMENTS}

The authors wish to acknowledge the cooperation of Drs. J. E. Muse, Jr., T. Nelson Carey, A. H. Crowther, Baltimore, Maryland; R. S. McVaugh, Taneytown, Maryland; W. C. Stone, Westminster, Maryland; Paul Padget, Veterans Hospital, Fort Howard, Maryland; A. A. Pearre, Frederick, Maryland; Capt. J. M. Lipnik, Fort Meade, Maryland; and Col. D. J. Waligora, Fort Jay, New York, in bringing these patients to our attention. Miss Ann Meredith rendered valuable technical assistance. Grateful acknowledgment is extended to Capt. H. L. Ley, Jr., of the Virus and Rickettsial Disease Department of the Army Medical Department Research and Graduate School, for assistance in performing Chloromycetin assays, and to the Maryland State Health Department Laboratory for collaboration in the bacteriological study.

\section{BIBLIOGRAPHY}

1. Ehrlich, J., Bartz, G. R., Joslyn, D. A., and Burkholder, P. R., Chloromycetin, a new antibiotic from a soil actinomycete. Science, 1947, 106, 417.

2. Smith, R. M., Joslyn, D. A., Gruhzit, O. M., McLean, I. W., Jr., Penner, M. A., and Ehrlich, J., Chloromycetin, biological studies. J. Bact., 1948, 55, 425.

3. Controulis, J., Rebstock, M. C., and Crooks, H. M., Jr. J. Am. Cl. Sc., 1949, in press.

4. Smadel, J. E., Jackson, E. B., Ley, H. L., Jr., and 
Lewthwaite, R., Comparison of synthetic and fermentation chloramphenicol (Chloromycetin) in rickettsial and viral infection. Proc. Soc. Exper. Biol. \& Med., 1949, 77, 191.

5. Smadel, J. E., and Jackson, E. B., Chloromycetin, an antibiotic with chemotherapeutic activity in experimental rickettsial and viral infections. Science, 1948, 106, 418.

6. Smadel, J. E., Woodward, T. E., Ley, H. L., Jr., Philip, C. B., Traub, R., Lewthwaite, R., and Savoor, S. R., Chloromycetin in the treatment of scrub-typhus. Science, August 13, 1948, 108, 160.

7. Woodward, T. E., Smadel, J. E., Ley, H. L., Jr., Green, R., and Manikikar, D. S., Preliminary report on the beneficial effect of Chloromycetin in the treatment of typhoid fever. Ann. Int. Med., 1948, 49, 131.

8. Joslyn, D. A., and Galbraith, M., A turbidimetric method for the assay of antibiotics. J. Bact., 1947, 54, 26.

9. Ley, H. L., Jr., Smadel, J. E., and Crocker, T. T., Administration of Chloromycetin in normal human subjects. Proc. Soc. Exper. Biol. \& Med., 1948, $69,9$.

10. Goodpasture, E. W., and Anderson, K., The problem of infection as prevented by bacterial invasion of the chorioallantoic membrane of the chick embryo. Ann. J. Path., 1937, 13, 149.

11. Smadel, J. E., Leon, H. E., Ley, H. L., Jr., and Varela, G., Chloromycetin in the treatment of patients with typhus fever. Proc. Soc. Exper. Biol. \& Med., 1948, 68, 12.

12. Payne, E. H., Knaudt, J. A., and Palacios, S., Treatment of epidemic typhus with Chloromycetin. J. Trop. Med. \& Hyg., 1948, 51, 68.

13. Pincoffs, M. C., Guy, E., Lister, L. W., Woodward, T. E., and Smadel, J. E., The treatment of Rocky Mountain spotted fever with Chloromycetin. Ann. Int. Med., 1948, 29, 656.

14. Spink, W. W., Hall, W. H., Shaffer, J. M., and Braude, A. I., Human brucellosis. Its specific treatment with a combination of streptomycin and sulfadiazine. J. A. M. A., 1948, 136, 382.

15. Spink, W. W., Hall, W. H., Shaffer, J. M., and Braude, A. I., Treatment of brucellosis with streptomycin and a sulfonamide drug. J. A. M. A., 1949, 139, 352.

16. Spink, W. W., Braude, A. J., Castaneda, M. R., and Goytia, R. S., Aureomycin therapy in human brucellosis. J. A. M. A., 1948, 138, 1145.

17. Bryer, M. S., Schoenbach, E. B., Chandler, C. A., Bliss, E. A., and Long, P. H., Aureomycin, experimental and clinical investigations. J. A. M. A., 1948, 138, 117.

18. Ross, S., Burke, F. G., Rice, E. C., Schoenbach, E. B., Bischoff, H., and Washington, J. A., Aureomycin, preliminary report of a clinical trial. Clin. Proc. Child. Hosp., Washington, D. C., 1948, 4, 315.

19. Woodward, T. E., Chloromycetin and aureomycin: therapeutic results. Ann. Int. Med., 1949. In press. 